\title{
Gold Drugs: Mechanism of Action and Toxicity
}

\author{
Sabine L Best and Peter J Sadler \\ Department of Chemistry, Birkbeck College, University of London, Gordon House \\ and Christopher Ingold Laboratories, 29 Gordon Square, London WC1H OPP, UK
}

Gold drugs are still amongst the most efficacious for the treatment of rheumatoid arthritis. Their mechanism of action, as well as the molecular basis of their side-effects, remain poorly understood. Current theories are reviewed, including recent potential breakthroughs. The interaction of gold(III) with peptides and proteins and its immunochemical implications are discussed.

Ninety elements occur naturally on earth of which 9 are radioactive. Eighty-one elements are therefore potentially available to support life, of which 61 are metals. It is believed that about 25 are essential for human life but our knowledge of the biochemistry of several of these (e.g. $\mathrm{V}, \mathrm{Ni}, \mathrm{Sn}$ ) is poor. In general, therefore, there is enormous scope for the use of inorganic compounds in medicine, and a need for research in this area. Metals currently used in medicine include gold in antiarthritic agents, platinum in anticancer drugs, lithium for manic depression, bismuth in anti-ulcer drugs, and silver and mercury in antimicrobial agents (1). The effectiveness of ruthenium complexes as anti-metastatic agents with potential use in cancer therapy is currently receiving much attention (2). However, the potential of inorganic metal compounds as drugs has yet to be fully explored. With the exception of platinum, which has attracted the most research efforts because of its importance in the therapy of some types of cancer, and which is now generally thought to be effective by interaction with DNA, the mechanism of action of other inorganic drugs is mostly unknown.

One of the problems of inorganic drugs is their side-effects. For gold drugs used in the therapy of

\footnotetext{
* Hypersensitivity is an adaptive immune response occurring in an exaggerated or inappropriate form causing tissue damage. It is a characteristic of the individual and is manifested on second contact with the particular antigen (in this case gold drugs). Delayed-rype hypersensitivity takes more than 12 hours to develop and is mediated primarily by $\mathrm{T}$ cell and macrophages.
}

rheumatoid arthritis (RA), about $30 \%$ of patients experience side-effects which often necessitate discontinuation of therapy (3). The main side-effect is a delayed-type hypersensitivity* (4) which manifests itself in an itchy skin rash. A more detailed understanding of the toxicity of gold drugs might make their use safer and could lead to the synthesis of less toxic compounds.

\section{STRUCTURES OF GOLD DRUGS}

Gold(I) has a very high preference for 'soft' ligands such as sulfur (thiolates) and phosphorus (phosphines), with little affinity for oxygen ligands and only weakly for nitrogen. Linear two-coordination predominates but trigonal or tetrahedral coordination is possible.

There are two main classes of gold drugs in current chemical use:

1 Injectable gold(I) thiolates such as aurothiomalate, aurothioglucose and aurothiopropanol sulfonate which are major ingredients of Myocrisin TM, Solganol ${ }^{T M}$ and Allocrysin ${ }^{\mathrm{T} M}$, respectively, and

2 The oral complex (2,3,4,6-tetra-O-acetyl-1-thioB-D-glucopyranosato-S) (triethylphosphine) gold (I) (auranofin).

The oral drug has a well defined structure with linear two-coordinate $\mathrm{Au}(\mathrm{I})$, but the injectable drugs are amorphous non-crystalline solids thought to contain thiolate sulfur-bridged oligomers and ring structures (Figure 1). A hexameric ring structure has recently been demonstrated by X-ray crystallography for another 1:1 gold(I) thiolate complex (5). 


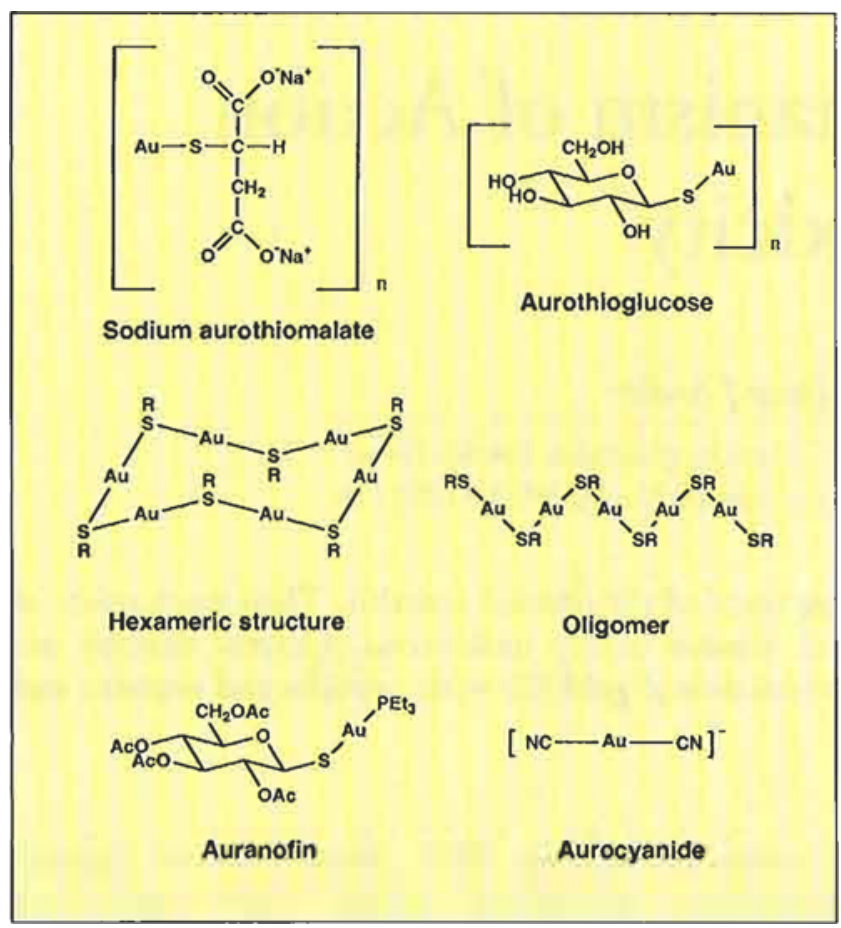

Figure 1 Structures of some widely used gold drugs and the metabolite dicyanogold(I)

\section{OTHER POTENTIAL USES OF GOLD IN THERAPY}

Other possible uses of gold compounds in therapy have been suggested. Apart from its antiarthritic properties, aurothiomalate has been shown to have anti-leishmanial activity in hamsters(6). More recently, auranofin has been proposed for the treatment of psoriasis (7). Bis(thioglucose)gold(I) has been found to inhibit the replication of one strain of the HIV virus in vitro (8). The inhibition of the virus was suggested to be due to the interaction of gold(I) with a cysteine residue in a surface protein of the viral envelope (8). It was shown separately that bis(thioglucose)gold(I) inhibits solubilized reverse transcriptase in vitro (8). A metabolite of all gold drugs is dicyanogold(I) (9), which has been proposed for the treatment of AIDS due to its ability to penetrate cells rapidly and its suggested low toxicity (10).

\section{PROPOSED MECHANISMS OF ACTION OF GOLD DRUGS}

The mechanism of action of gold drugs is still unknown. However, various models for the effectiveness of chrysotherapy have been put forward.
The elevated copper levels in RA that can be correlated to the severity of the disease, have led to the suggestion that antiarthritic drugs like penicillamine and aurothiomalate act by sequestering labile and potentially disease-inducing forms of copper, e.g. copper bound to human serum albumin (11).

The three widely used gold drugs, aurothiomalate, aurothioglucose and auranofin, have been shown to inhibit protein kinase C (12), a metallo-enzyme containing $\mathrm{Zn}^{2+}$ bound to cysteine and histidine residues, which plays a crucial role in intracellular signal transduction by phosphorylating serine/threonine residues in protein. The inhibition of protein kinase $C$ has been suggested as a possible mode of action for the therapeutic antirheumatic action of gold drugs $(12,13)$.

Gold binding to thiol groups on the hexose transport protein in the membranes of blood cells can alter glucose metabolism and thus may affect the activity and viability of cells (14).

Recently, a new hypothesis for the mode of action of gold drugs has been put forward. Au(I) may occupy the cysteine-rich metal binding site in transcription factors containing the zinc finger motif, thus inhibiting binding to their specific DNA response elements in promoter and enhancer regions of genes (15).

Aurothiomalate may be activated through interaction with cyanide which is produced by activated polymorphonuclear leukocytes (16). Cyanide can readily replace the thiomalate ligand from aurothiomalate in vitro (17) and aurocyanide $\left[\mathrm{Au}(\mathrm{CN})_{2}\right]^{-}$has been shown to be a metabolite of gold drugs in vivo (9). Interestingly, the blood of smokers contains a higher level of thiocyanide, the precursor of cyanide, and the uptake of gold by red blood cells is also enhanced in smokers (18). Aurocyanide may be the active metabolite of gold drugs since it inhibits various functions (e.g. the oxidative burst) of polymorphonuclear leukocytes and other cells, and these cellular interactions may lead to the therapeutic effects (3). Oxygen radical production (eg superoxide, $\mathrm{O}_{2}^{-}$by cells during the respiratory burst is essential to the immune response towards invading bacteria, but excessive production of these radicals has been linked to the chronic inflammation encountered in RA.

Gold compounds may act by suppressing the immunological processes that underlie the chronic inflammation of RA (19). Aurothiomalate (20) and auranofin (19) can inhibit the functional capacity of monocytes to induce $\mathrm{T}$ lymphocyte proliferation in vitro. Both monocytes and $T$ lymphocytes are white blood cells performing different functions in the 


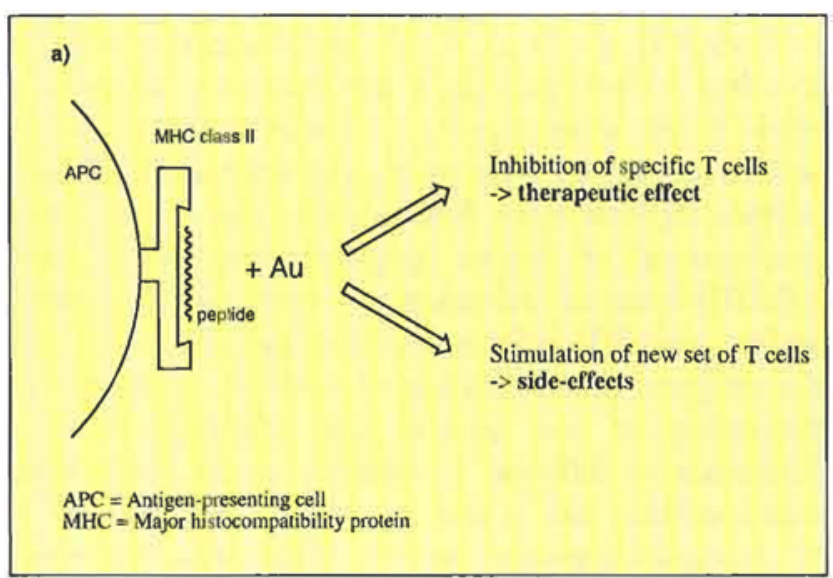

Figure 2a Proposed $M H C$ class $I I$ - peptide - gold - T cell

immune system. More recently, it has been shown that $\mathrm{AuCl}_{4}-$ can inhibit the peptide-dependent proliferation of a $\mathrm{T}$ cell clone in vitro in a concentration dependent manner (21). The hypothesis that gold has the ability to alter the MHC-class II-peptidet complex that is recognised by $\mathrm{T}$ cells has the advantage of providing an explanation for both the therapeutic and the toxic effects of chrysotherapy. Modification of possible 'autoimmune peptide-MHC complexes' by gold would inhibit the stimulation of autoaggressive $T$ cells and, in turn, elicit gold-specific $T$ cells that could be responsible for the delayed type hypersensitivity sideeffects (22) (Figure 2a). It has been suggested that gold binding to the MHC class II protein rather than to the bound peptide inhibits $T$.cell proliferation in contrast to nickel(II) which, it has been suggested, interacts with the peptide (22). However, it has recently been shown that aurothiomalate inhibits $\mathrm{T}$ cell recognition of peptides containing two or more cysteine residues, possibly due to the formation of chelate complexes (23). Gold-specific T cell clones that proliferate when exposed to gold(I) and gold(III) compounds in vitro

[ $\dagger$ ] In the cell mediated immune response, foreign proteins are processed in antigen-presenting cells such as monocytes by proteolytic enzymes. A resultant peptide is presented on the surface of the cell bound to a membrane protein, the so-called major histocompatibility complex (MHC) protein. The complex formed by peptide and MHC protein is recognized by $T$ cells. There are two main types of ' $T$ ' cells recognizing different MHC proteins: cytotoxic $\left(C D 8^{+}\right)$' MHC class I proteins, while helper $\left(\mathrm{CD}^{+}\right) \mathrm{T}^{-}$cells recognize MHC II Class proteins, T. helper cells stimulate inflammatory and antibody responses by releasing cytokines and by direct intercellular contact with B cells. Rheumatoid arthritis as well as delayed-type hypersensitivity are linked to $T$ helper cells which recognize peptides bound to MHC class II proteins.

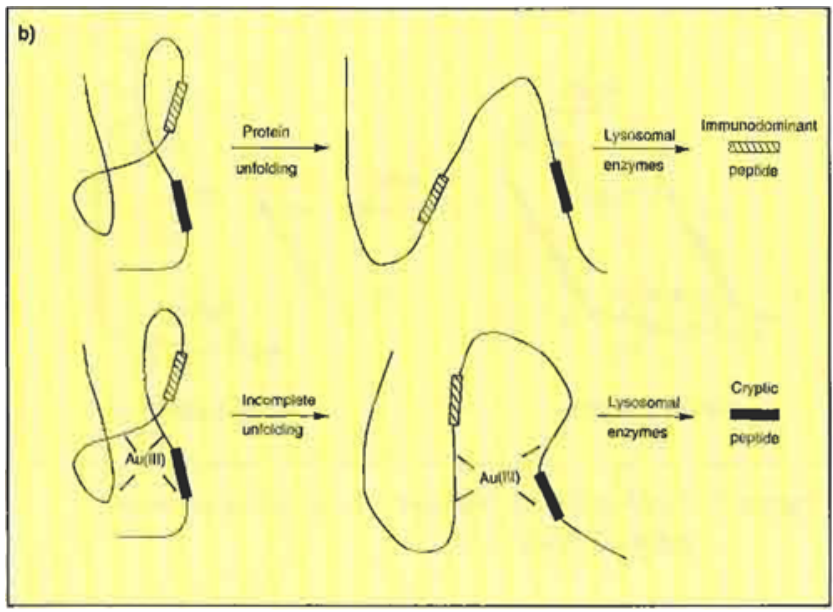

Figure $2 \mathrm{~b}$ Concept of the scission of different peptides from $a$ protein alone or reacted with $A u(I I I)$, adapted from [24]

have been isolated from patients who have developed such hypersensitivity reactions (21). Two recent reviews summarise the current view of the effect of gold on $\mathrm{T}$ cell recognition $(22,24)$.

\section{INTERACTION OF GOLD (I) WITH ALBUMIN}

The chemistry (25-27), biochemistry (28, 29), pharmacology (30) and the more clinical aspects (3) of gold drugs have been reviewed. The major binding site for gold drugs in plasma is the free thiol group of cysteine-34 of human serum albumin $(28,29)$. Evidence for an albumin-gold-glutathione complex as metabolite of auranofin has been reported (31).

Albumin is the major protein in blood plasma, concentration ca $0.63 \mathrm{mM}$. It consists of a single polypeptide chain of 585 amino acids arranged in three largely helical domains folded into a globular heart-shaped molecule. There are 6 disulfide bridges in each domain, except domain I which is missing a cysteine residue and in consequence has a free thiol at cysteine in sequence position 34. Binding of auranofin and derivatives to the free thiolate group of cysteine- 34 of albumin induces a structural transition, the effect of which can be observed on ${ }^{1} \mathrm{H}-\mathrm{NMR}$ resonances of histidine-3 of the protein $(32,33)$. Such a communication between histidine- 3 and cysteine- 34 may be explained by small changes in the arrangement of intervening helices 1 and 2 of domain I of the protein. This may be mediated by a cis-trans isomerization of proline-35, changing the environment of cysteine-34 from a buried to an exposed one 


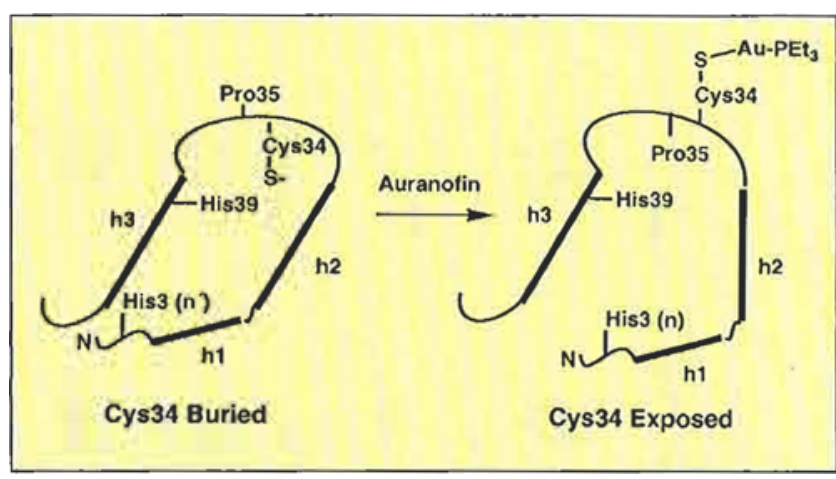

Figure 3 Gold-induced "flip-out" of Cys-34 of albumin, adapted from [35]

(Figure 3) (33). This structural transition induced by gold(I) binding may have important consequences in signalling degradation of albumin and also in copper homeostasis in patients undergoing chrysotherapy, as histidine-3 is involved in the $\mathrm{N}$-terminal copper binding site of albumin. Kinetic investigations of the reaction of albumin with auranofin show that the reaction is first order with respect to albumin but zero order with respect to auranofin (34), findings that are consistent with crevice-opening and exposure of cysteine-34 being the rate-limiting step (35). The rate of reaction of auranofin with albumin is fast implying that the intact drug has only a short half-life in plasma (a few seconds) (34). The structural transition of albumin induced by gold drugs has also been observed by NMR studies of intact blood plasma (35). Gold modulation of cysteine-34 could be important in therapy since albumin catabolism in RA patients is known to be excessively high.

\section{TOXICITY OF GOLD DRUGS}

It has recently been suggested that gold(III) produced from gold(I) drugs might be involved in the toxic sideeffects encountered in chrysotherapy. The chronic treatment of mice with gold(I) drugs results in the production of $T$ cells that are stimulated not by gold(I) but by gold(III) (36) and patients with gold-induced dermatitis show significant lymphocyte proliferation in response to gold(III) but not to gold(I) [37]. Reaction of the model antigen bovine ribonuclease (RNase) A

[ $\ddagger$ ] Immunodominant peptides are those peptides of a protein antigen that dominate the $T$ cell response to this antigen. In contrast, cryptic peptides are peptides that do not elicit a $\mathrm{T}$ cell response under normal conditions, but induce a response when their presentation is up-regulated for a particular reason (38). with $\mathrm{Au}(\mathrm{III})$ results in $\mathrm{T}$ cell sensitization in mice to so-called 'cryptic peptides' $\ddagger$ derived from this protein while $T$ cells from mice injected with RNase alone are sensitized only to a common, the immunodominant, peptide derived from RNase (38). The scission and presentation of cryptic peptides may arise from gold(III)-induced oxidation of methionine residues and/or gold(III)-induced conformational changes in the antigenic protein leading to a different intracellular processing of the protein and therefore to the formation of different antigenic peptides. The novel aspect of these data is that the metal is not involved in the recognition process between MHC class II protein, peptide and $\mathrm{T}$ cell, but affects the prior processing step of a protein altered by the effect of the metal (gold) (38), (Figure 2b).

Strong oxidants are required to convert gold(I) into gold(III) but they are potentially available in vivo in inflammatory situations. For example myeloperoxidase, in the presence of $\mathrm{H}_{2} \mathrm{O}_{2}$ and $\mathrm{Cl}^{-}$, can oxidize aurothiomalate in vitro via production of $\mathrm{ClO}^{-}$ [39]. Hypochlorite $\left(\mathrm{ClO}^{-}\right)$is synthesized by the enzyme myeloperoxidase of phagocytic cells from $\mathrm{H}_{2} \mathrm{O}_{2}$ and $\mathrm{Cl}^{-}$during the oxidative burst, and can oxidize gold(I) in aurothiomalate, aurothioglucose and auranofin to gold(III) (40).

\section{INTERACTION OF GOLD(III) WITH PEPTIDES}

These findings recently led us to examine the interaction of gold(III) with peptides. Most investigations of the biological chemistry of gold have, for obvious reasons, focused on gold(I) and its interaction with naturally occurring thiols. Investigations concerning the biological chemistry of gold(III) are scant despite the use of $\mathrm{AuCl}_{4}^{-}$as a heavy atom label in protein X-ray crystallography (41).

Only a few investigations have been carried out on reactions of gold(III) with amino acids and peptides and most of these have focused on the sulfurcontaining amino acids cysteine (a thiol) and methionine (a thioether). Gold(III) can oxidize disulfide bridges in albumin (42), and the reaction of tetrachloroaurate with cysteine $(\mathrm{RSH})$ follows the equation $(43,44)$ :

\footnotetext{
$\mathrm{NaAuCl}_{4}+3 \mathrm{RSH} \longrightarrow \mathrm{RSAu}+\mathrm{RSSR}+3 \mathrm{HCl}+\mathrm{NaCl}$

Cystine (RSSR) can reduce $\mathrm{KAuBr}_{4}$ with the formation of metallic gold (45):
} 


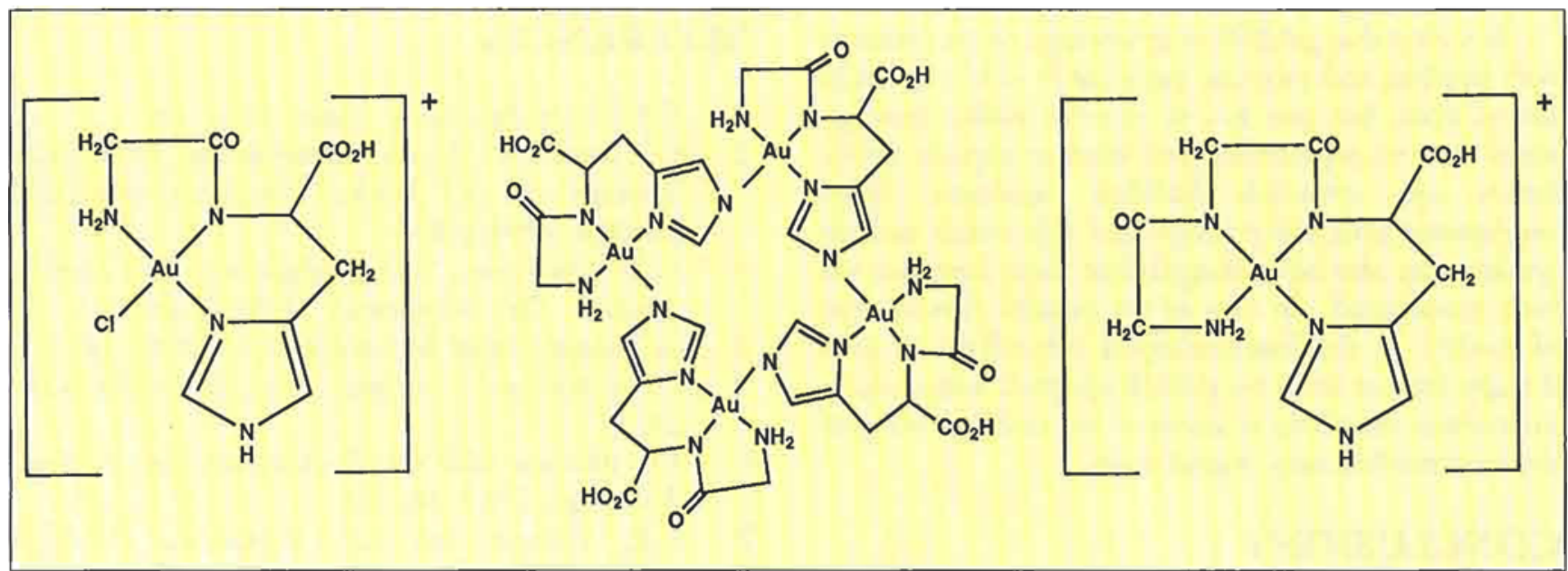

Figure 4 Structures of some crystallized gold(III)-peptide complexes:

$\left[\mathrm{Au}\left(\mathrm{Gly}-\mathrm{L}-\mathrm{His}-\mathrm{H}_{.}\right) \mathrm{Cl}\right] \mathrm{Cl} \cdot 3 \mathrm{H}_{2} \mathrm{O},\left[\mathrm{Au}\left(\mathrm{Gly}-\mathrm{L}-\mathrm{His}-\mathrm{H}_{-3}\right)\right]_{4} \cdot 1 \mathrm{OH}_{2} \mathrm{O}[49]$ and $\left[\mathrm{Au}\left(\mathrm{Gly}-\mathrm{Gly}-\mathrm{L}-\mathrm{His}-\mathrm{H}_{.2}\right] \mathrm{Cl} \cdot \mathrm{H}_{2} \mathrm{O}[5 \mathrm{O}]\right.$

$$
\begin{gathered}
3 \mathrm{RSSR}+10 \mathrm{KAuBr}_{4}+18 \mathrm{H}_{2} \mathrm{O} \longrightarrow 6 \mathrm{RSO}_{3}^{-} \\
+10 \mathrm{Au}^{0}+40 \mathrm{Br}^{-}+10 \mathrm{~K}^{+}+36 \mathrm{H}^{+}
\end{gathered}
$$

The reaction is thought to proceed via immediate $S-S$ bond scission to form the sulfenic acid which is further oxidized to the sulfonic acid $\mathrm{RSO}_{3} \mathrm{H}$.

Insulin, which consists of two peptide chains (A and $B$ ) joined by two disulfide bridges, can be oxidized by tetrabromoaurate (42), and the oxidation of disulfides with consequent disruption of the secondary and tertiary structures of proteins by gold(III) compounds could play an important role in the toxicity of gold(III) compounds, hence precluding their use in chrysotherapy (45).

The amino acid methionine and methionine residues in proteins can also be oxidized by gold(III) $(46,47)$ and the reactions are fast and stereospecific. The addition of tetrachloroaurate to native ribonuclease causes the formation of aggregates. However, when the protein is partially unfolded by lowering the $\mathrm{pH}$, the addition of tetrachloroaurate causes oxidation of methionine residues to methionine sulfoxide (48).

Little is known about the interaction of gold(III) with other amino acids in peptides and proteins. Only two crystal structures of gold(III) complexes of peptides have previously been reported, both containing the dipeptide glycyl-L-histidine (Gly-L$\mathrm{His})$ : $\left[\mathrm{Au}\left(\mathrm{Gly}-\mathrm{L}-\mathrm{His}-\mathrm{H}_{-1}\right) \mathrm{Cl}\right] \mathrm{Cl} \cdot 3 \mathrm{H}_{2} \mathrm{O}$ and $[\mathrm{Au}(\mathrm{Gly}-\mathrm{L}-$ His- $\left.\left.\mathrm{H}_{-3}\right)\right]_{4} \cdot 10 \mathrm{H}_{2} \mathrm{O}$ [49]. The former was crystallized from a 1:1 reaction mixture at low $\mathrm{pH}(1.5-2)$ and is a square-planar complex in which $\mathrm{Au}(\mathrm{III})$ binds to the imidazole $\delta \mathrm{N}$ of $\mathrm{His}$, one deprotonated peptide nitrogen and the amino group of Gly 1, with a chloride ion in the fourth coordination site. When these crystals were dissolved at higher $\mathrm{pH}$ (6-7), a cyclic tetramer with the metal bridging between the $\delta \mathrm{N}$ and $\epsilon \mathrm{N}$ atoms of two different Gly-L-His molecules was obtained (Figure 4) (49). We have recently prepared the fourcoordinate complex of gold(III) with the tripeptide Gly-Gly-L-His (Figure 4) (50), the first Au(III)tripeptide complex to be reported. This forms readily via one intermediate in strongly acidic solutions $(\mathrm{pH}$ 1.5).

We have recently examined potential binding sites for gold(III) on peptides using the monodentate compound $[\mathrm{Au}(\mathrm{dien}) \mathrm{Cl}] \mathrm{Cl}_{2}$. In the simple tripeptide glycylglycylglycine, the amino group is the only binding site, with no evidence found for an involvement of the carboxyl group (51). In histidinecontaining peptides, the binding sites for gold(III) include the His $\delta$ and $\epsilon$ nitrogens and the $\mathrm{N}$-terminal amino group. Species in which the imidazole ring acts as a bridging ligand between two gold(III) moieties are found at $\mathrm{pH}$ values as low as $5(51)$.

Gold(III) is one of the strongest inducers of across-the-ring ionization of His $\in \mathrm{NH}$ when bound to His $\delta \mathrm{N}$ of an imidazole ring of histidine. It lowers the $\mathrm{pK}_{\mathrm{a}}$ of the so-called 'pyrrole nitrogen' (52) from above 14 in free histidine to about 9, when gold(III) is bound to His $\delta \mathrm{N}$, the so-called 'pyridine nitrogen' (50). Comparable values have been reported only for $\mathrm{Ru}(\mathrm{III})$ with a $\mathrm{pK}_{\mathrm{a}}$ value of 8.7 (53), $\mathrm{Co}$ (III) with a $\mathrm{pK}_{\mathrm{a}}$ value of $9.6(54)$ and $\mathrm{Hg}(\mathrm{II})$ with a $\mathrm{pK}_{\mathrm{a}}$ value of 9.6 also (55). For comparison, copper(II) complexation lowers the $\mathrm{pK}_{\mathrm{a}}$ value of the pyrrole nitrogen to values of about 11 (52) and palladium(II) to $10.8(56)$ and $11.3(50)$. 
It is clear that gold(III) may undergo redox reactions with peptides and proteins, particularly involving sulfur amino acids, but also has an unusual ability amongst metal ions to deprotonate and bind to peptide amide bonds and cross-link histidine imidazole rings. Interactions with other amino acid side-chains such as tyrosine can also be envisaged, but these have not yet been investigated. In view of the possible involvement of $\mathrm{Au}(\mathrm{III})$ in the immunological side-effects of gold therapy, further work on gold(III)-peptide and -protein interactions may help to improve our understanding of the immunochemistry of gold drugs.

\section{CONCLUSIONS}

It is possible that gold drugs act upon different stages of rheumatoid arthritis, but a final statement must await further progress into the aetiology of this complex disease. The first action might be on the central recognition process of $\mathrm{T}$ helper cells (white blood cells) which recognize a disease-inducing ('autoimmune') peptide bound to an MHC class II protein on the surface of immunological cells. As RA is now generally considered to be an auto-immune disease, this might be a peptide derived from selfproteins. An inhibition of the disease-triggering $\mathrm{T}$ cell response by gold might be its first effect. This inhibition might be due to interaction of gold(I) or gold(III) with MHC class II protein or bound peptide. Toxic side-effects might in turn be elicited by this same mechanism or might be due to the expression of cryptic peptides derived from a protein altered by gold. On a second level, the inhibition of the oxidative burst of polymorphonuclear lymphocytes by gold might alleviate secondary effects of the chronic inflammation in the affected joints. The active metabolite responsible for such inhibition appears to be $\left[\mathrm{Au}(\mathrm{CN})_{2}\right]^{-}$which is a universal metabolite formed from both injectable and oral gold drugs and may play a key role in the pharmacology of gold.

\section{ABOUT THE AUTHORS}

Sabine Best has recently completed her $\mathrm{PhD}$ at Birkbeck College, University of London on the biological chemistry of gold, and is currently a research fellow in the School of Biological Sciences at Queen Mary and Westfield College, London. Peter Sadler has just taken up the Crum Brown Chair of Chemistry at the University of Edinburgh after 23 years at Birkbeck College. His major research interests lie in the chemistry of metals in medicine.

\section{REFERENCES}

$1 \quad$ P. J. Sadler, Adv. Inorg. Chem., 1991, 36, 1

2 G. Sava, in 'Metal Compounds in Cancer Therapy', ed. S.P. Fricker, Chapman and Hall, London, 1994, p.65

3 G.D. Champion, G.G. Graham and J.B. Ziegler, Baillieres Clin. Rheumatol., 1990, 4, 491

4 L. Treagan, Metal Ions in Biol. Syst., 1983, 16, 27

5 I. Schröter and J. Strähle, Chem. Ber., 1991, 124, 2161

6 J.L. Abruzzo and R.J. DeHoratius, Am. J. Trop. Med. Hyg., 1969, 18, 506

7 R.E. Thomas and R.A. Papandrea, Med. J. Austral., 1993, 158, 720

8 T. Okada, B.K. Patterson, S.-Q. Ye and M.E. Gurney, Virology, 1993, 192, 631

9 R.C. Elder, Z. Zhao, Y. Zhang, J.G. Dorsey, E.V. Hess and K.J. Tepperman, J. Rheumatol., $1993,20,268$

10 Y.F. Zhang, E.V. Hess, K.G. Pryhuber, J.G. Dorsey, K. Tepperman and R.C. Elder; Inorg. Chim. Acta, 1995, 229, 271

11 G.W. Rafter, J. Inorg. Biochem., 1990, 38, 261

12 C.W. Mahoney, C.E. Hensey, and A. Azzi, Biochem. Pharmacol., 1989, 38, 3383

13 T. Herlin, K. Fogh, N.O. Christiansen and K. Kragballe, Agents and Actions, 1989, 28, 121

14 P. E. McGowan, J.M. Campbell, J. Reglinski and W.E. Smith, Inorg. Chim. Acta, 1993, 210, 1

15 M.L. Handel, A. deFazio, C.K.W. Watts, R.O Day and R.L. Sutherland, Mol. Pharmacol., 1991, 40,613

16 R. Rudkowski, G.G. Graham, G.D. Champion and J.B. Ziegler, Biochem. Pharmacol., 1990, 39, 1687

17 G.G. Graham, J.R. Bales, M.C. Grootveld and P.J. Sadler, J. Inorg. Biochem., 1985, 25, 163

18 G.G. Graham, T.M. Haavisto, P.J. McNaught, C.D. Browne, and G.D. Champion, J. Rheumatol., 1982, 9, 527

19 G. Salmeron and P.E. Lipsky, J. Rheumatol. Suppl., 1982, 8, 25

20 P.E. Lipsky and M. Ziff, J. Clin. Invest., 1977, 59, 455

21 P. Romagnoli, G.A. Spinas and F. Sinigaglia, J. Clin. Invest., 1992, 89, 254

22 F. Sinigaglia, J. Invest. Dermatol., 1994, 102, 398

23 P. Griem, K. Takahashi, H. Kalbacher and E. Gleichmann, J. Immunol., 1995, 155, 1575

24 P. Griem and E. Gleichmann, Curr. Opin. Immunol., 1995, 7, 831 
25 P.J. Sadler, Gold. Bull., 1976, 9, 110

26 D.H. Brown and W.E. Smith, Chem. Soc. Rev., $1980,9,217$

27 P.J. Sadler and R.E. Sue, Metal-Based Drugs, 1994, 1, 107

28 C.F. Shaw III, Inorg. Perspect. Biol. Med., 1979, 2, 287

29 C.F. Shaw III, Comments Inorg. Chem., 1989, 8, 233

30 A.J. Lewis and D.T. Walz, Prog. Med. Chem., $1982,19,1$

31 C.F. Shaw III, A.A. Isab, M.T. Coffer and C. Mirabelli, Biochem. Pharmacol., 1990, 40, 1227

32 O.M. Ni Dhubhghaill, P.J. Sadler and A. Tucker, J. Am. Chem. Soc., 1992, 114, 1118

33 J. Christodoulou, P.J. Sadler and A. Tucker, Eur. J. Biochem., 1994, 225, 363

34 J.R. Roberts, J. Xiao, B. Schliesman, D.J. Parsons and C.F. Shaw III, Inorg. Chem., 1996, 35,424

35 J. Christodoulou, P.J. Sadler and A. Tucker, FEBS Letters, 1995, 376, 1

36 D. Schuhmann, M. Kubickamuranyi, J. Mirtschewa, J. Gunther, P. Kind and E. Gleichmann, J. Immunol., 1990, 145, 2132

37 J. Verwilghen, G.H. Kingsley, L. Gambling and G.S. Panayi, Arthritis Rheum., 1992, 35, 1413

38 P. Griem, K. Panthel, H. Kalbacher and E. Gleichmann, Eur. J. Immunol., 1996, 26, 279

39 B. Beverly and D. Couri, Fed. Proc., 1987, 46, 854

40 C.F. Shaw III, S. Schraa, E. Gleichmann, Y.P. Grover, L. Dunemann and A. Jagarlamudi, Metal Based Drugs, 1994, 1, 351
41 T.L. Blundell and L.N. Johnson, 'Protein Crystallography', Academic Press, New York, 1976

42 P.L. Witkiewicz and C.F. Shaw III, Chem. Commun., 1981, 1111

43 D.H. Brown and W.E. Smith, Am. Chem. Soc. Symp. Ser., 1983, 209, 401

44 W.E. Smith and J. Reglinski, Perspec. Bioinorg. Chem., 1991, 1, 183

45 C.F. Shaw III, M.P. Cancro, P.L. Witkiewicz and J.E. Eldridge, Inorg. Chem., 1980, 19, 3198

46 E. Bordignon, L. Cattalini, G. Natile and A. Scatturin, Chem. Commun., 1973, 878

47 G. Natile, E. Bordignon and L. Cattalini, Inorg. Chem., 1976, 15, 246

48 A.A. Isab and P.J. Sadler, Biochim. Biophys. Acta, $1977,492,322$

49 M. Wienken, B. Lippert, E. Zangrando and L. Randaccio, Inorg. Chem., 1992, 31, 1983

50 S.L. Best., T.K. Chattopadhyay, M.I. Djuran, R.A. Palmer, P.J. Sadler, I. Sóvágó and K. Varnagy, in preparation

51 S.L. Best, M.I. Djuran and P.J. Sadler, in preparation

52 R.J. Sundberg and R.B. Martin, Chem. Rev., $1974,74,471$

53 R.J. Sundberg and G. Gupta, Bioinorg. Chem., $1973,3,39$

54 W.J. Eilbeck and M.S. West, J. Chem. Soc., Dalton Trans., 1976, 274

55 C.A. Evans, D.L. Rabenstein, G. Geier and I.W. Erni, J. Am. Chem. Soc., 1977, 99, 8106

56 T.P. Pitner, E.W. Wilson and R.B. Martin, Inorg. Chem., 1972, 11, 738 